\title{
Stress-Strain Characteristics of a Cement-Bentonite Mix for a Barrier System: The Implication of Time and Curing
}

\author{
Alfred W. Opukumo ${ }^{1 *}$, Davidson E. Egirani ${ }^{1}$ and Reward K. Douglas ${ }^{2}$ \\ ${ }^{1}$ Department of Geology, Niger Delta University \\ Wilberforce Island, Bayelsa State, Nigeria \\ ${ }^{2}$ Faculty of Engineering, Niger Delta University \\ Wilberforce Island, Bayelsa State, Nigeria \\ ${ }^{*}$ Corresponding author's email: alfred.opukumo [AT] gmail.com
}

\begin{abstract}
For containment and water exclusion purposes, cement-bentonite (CB) barrier walls are usually built, with certain design criteria specified for the wall to fulfil intended purposes. While permeability is believed to be the most important criterion, it can be impacted by the stress-strain properties of the wall, which define the strength and stiffness. This study investigates the influence of curing time, confinement, rate of axial deformation, and quantity of cement (mix of Portland cement (PC) and ground granulated blast furnace slag (GGBS)) on the stress-strain properties of CB slurry walls. An unconfined compressive test supported by (i.e. UCT) undrained triaxial (UUT) tests were carried out on specimens prepared from two mix-designs (differentiated by the proportion of GGBS in the cement component) and cured 7, 14, 28, 60 and 90 days. Two rates of deformation $(1.0 \mathrm{~mm} / \mathrm{min}$ and $1.2 \mathrm{~mm} / \mathrm{min})$ were examined, using a range of confining pressure (i.e., $50-200 \mathrm{kPa}$ ) in the UUT. The results reveal that varying rate of deformation and the range of confining pressures have no clear influence on the mechanical properties (e.g., deviator stress, shear strength and stiffness) of the CB mix-designs. However, increased curing time, and the proportion of GGBS significantly improved these properties. An increased proportion of GGBS enhances early strength. Thus, further work needs to be done to establish a balance between adequate strength and adequate flexibility of $C B$ walls in order to not compromise permeability.
\end{abstract}

Keywords - Cement-bentonite, Curing, Strength, Containment, Exclusion

\section{INTRODUCTION}

The application of slurries of soil-cement-bentonite (SCB), cement-bentonite (CB) and soil-bentonite (SB) for various engineering projects world over is a known technology. This technology is applicable in remediation (containment) of contaminated land, water exclusion to aid excavation works, and stability of excavation/drill walls. Slurries are applied to trenches, which cure in situ forming subsurface barrier walls normally keyed to an impervious stratum in order to form a bottom seal, to contain ground pollutants, exclude groundwater or retard flow of groundwater to control flooding (e.g., levees). Royal et al. [1] reported two construction techniques of CB cut-off barriers, namely 'single phase' where CB slurry pumped into a trench supports the excavation walls and thereafter cures in situ to form a wall; and 'dual phase' where only bentonite slurry is pumped into the trench to stabilise its walls. Subsequently, CB slurry is pumped into the excavation, displacing supporting bentonite slurry and curing to form the barrier wall. However, [2] and [3] had suggested that the two techniques were rather used for different materials. The 'single phase' for CB walls while the 'double phase' was for SB walls. Since the construction of CB walls involves only one major operation, they are easier and quicker to construct compared to SB walls [2 - 3].

Generally, Portland cement (PC) is the commonest cementitious material used all over the globe (about $95 \%$ of the world, according to [4] to build cement-bentonite walls. However, for both economic and environmental reasons, inorganic waste materials (particle size like or smaller than that of PC) classified as pozzolans are commonly used as partial PC replacement materials (i.e., additives). These pozzolans are required to have the ability to improve or achieve special properties of the slurry paste [5]. They may be supplied separately and are added to the paste at mixing or are blended into PC at manufacture. However, the blended PC holds the disadvantage of a fixed proportion of the replacement material while the proportion of replacement material can be varied if supplied separately. According to [4], pozzolanic or latent hydraulic additives are materials that contain active silica $\left(\mathrm{SiO}_{2}\right)$ and are not cementitious in themselves except, in finely divided form, in moisture condition. Calcium hydroxide $\left(\mathrm{Ca}(\mathrm{OH})_{2}\right)$ reacts with these materials at ambient temperature to form cementitious compounds. These include: Fly ash also known as pulverized fuel ash (PFA), ground granulated blast furnace slag (GGBS), condensed silica fume (CSF) (often called microsilica), 
calcined clay or shale, rice husk ash, and natural pozzolans (some volcanic ashes and diatomaceous earth) which are not extensively used [4].

However, [1] identified GGBS and PFA as the common cement replacement materials used to achieve a standard specified permeability while maintaining pumpable and economic slurry. On the contrary, CIRIA Special Publication SP106, 1996 cited in [6] had earlier contended that only GGBS was effective to achieve the $1 \times 10^{-9} \mathrm{~m} / \mathrm{s}$ permeability and the $5 \%$ failure strain performance specification criteria. However, the resultant engineering properties for PC and GGBS mix (with $>80 \%$ GGBS) in cement-bentonite is unknown.

The wide range of importance and engineering applications of CB slurry walls all over the world and especially in the United Kingdom [7 - 8] informed this study, which investigated the stress-strain conditions that may impair the serviceability of CB wall using PC and GGBS mix as cement. Although testing of CB barrier walls under drained conditions was desired to understand their long-term behaviour, only undrained properties could be studied due to time constraints.

\subsection{Theoretical concept}

\subsubsection{Bentonite clay}

Bentonite-clay is a mineral composed largely of hydrous sodium magnesium calcium aluminium silicate called montmorillonite, the commonest mineral of smectite, with calcium $\left(\mathrm{Ca}^{2+}\right)$, sodium $\left(\mathrm{Na}^{+}\right)$, and to a less extent aluminium $\left(\mathrm{Al}^{3+}\right)$ exchangeable cations [6,9]). This forms the classification of bentonites based on the dominant mineral element, into mainly $\mathrm{Ca}$ - and $\mathrm{Na}$ - bentonites [6]. Na-bentonite clay has high adsorption capacity and low permeability because of its capacity to exchange for cations and high exposed surface area, which are the key properties required of a clay for the construction of barrier walls [10]. Besides, Ca-bentonite can also exhibit similar characteristics, but higher quantities will be needed compared to the Na type bentonite [11].

$\mathrm{Na}$ exchanged bentonite swells above 10 times its initial volume and this can result in the complete dissociation of the crystal $[6,12]$. Molecules of water are drawn by Na-bentonite allowing very minimal free-water space in the lattice. This significantly decreases hydraulic conductivity of Na-bentonites to less than $10^{-11} \mathrm{~m} / \mathrm{s}[11]$. A value of $10^{-9} \mathrm{~m} / \mathrm{s}$ or less was argued satisfactory for barrier walls $[6,13]$.

Bentonites have variable applications in the industry and other activities but are used mostly in civil engineering works such as slurry barrier walls [6 - 7] and references cited in [11].

Na-bentonite is preferred for CB barrier wall construction due to its swelling properties. This bentonite naturally occurs in Wyoming, USA but in the UK and Europe, most of the bentonite used in CB slurries and grouts is Na activated Ca-bentonite [14]. The conversion of Ca-bentonite to Na-bentonite involves treatment with sodium carbonate (soda ash). Privett et al. [15] noted that formulation of Na-bentonite to in-house specifications often offer better performance since civil engineering bentonites do not have universal specification [3].

\subsubsection{Performance specifications for $\mathrm{CB}$}

A CB slurry and subsequent wall must exhibit certain characteristics in order for both to aid construction process and satisfy building purpose. These properties will include - for the slurry, viscosity for adequate pumping, density, bleed and setting time. Sufficient density of slurry is necessary for stabilising the trench walls. Xanthakos [16] states 1040 to $1150 \mathrm{~kg} / \mathrm{m}^{3}$ as the range for the initial density of CB slurry which rises to about $1250 \mathrm{~kg} / \mathrm{m}^{3}$ at postconstruction and placed a threshold level of $1300 \mathrm{~kg} / \mathrm{m}^{3}$ above which slurry is too dense impairing construction. Slurry with bleed over $5 \%$ has been noted unstable and less than $2 \%$ was recommended by [14], stating that GGBS partial cement replacement levels over $60 \%$ is necessary to reducing bleed to nil. This is the reason that 80 and $95 \%$ GGBS were adopted in the present study. Williams and Ghataora [3] had also acknowledged the need for a stable mix, as loss of water content results to loss of useful slurry volume, thus, specified $2 \%$ as maximum bleed levels. Setting time of more than 36 hours is recommended for slurry to remain workable after weekend or public holidays, acknowledging that early setting time may allow entrapment of more excavated spoil [3]. Also important is the quality of mix water used as this affects the slurry properties. Ions influence the behaviour of bentonite clay, for example, cations within montmorillonite can be exchanged for those of a higher valency in water with electrically charged ions and reduce repulsion leading to coagulation of particles [16]. Jefferis [17] suggested trigger concentrations of $50 \mathrm{mg} / \mathrm{l}$ magnesium, $250 \mathrm{mg} / \mathrm{l} \mathrm{calcium}$ and $500 \mathrm{mg} / \mathrm{l}$ sodium or potassium as acceptable in the mix water.

For the constructed $\mathrm{CB}$ wall, some of the most important characteristics include low permeability; adequate strength, and strain at failure to withstand ground movements as well as provide flexibility to avoid cracking; and chemical stability to withstand aggressive fluids. Previous studies on bentonite cut-off walls have indicated that an increase in concentration of organic contaminants that attacked the wall can be directly related to increasing permeability [18]. 
CB designers, therefore, must look for the best proportions of constituent materials to achieve these characteristics, both in the short and long terms. For instance, while $\mathrm{Na}^{+}$-bentonite clay is known for its ability to provide low permeability and wall flexibility, PC provides strength and rigidity and enhances setting.

CB slurry walls may be subjected to changes in physical and chemical conditions capable of altering their performance with time. For instance, changes in stress-strain conditions can alter strength, permeability and ultimately causing failure of the walls. Also, a highly aggressive environment raises concern over the durability and performance in the long-term, of CB walls as contaminants may attack the set material [6].

Although performance of freshly mixed samples and laboratory mixes may be said to be understood, long-term performance information of CB slurry walls in situ is scanty due to its recent application $[6,8,17,19]$. BRE, 1994 cited in [1, 20]; [6] and [19] suggested the following end-product performance specifications (for UK installations) for CB barrier walls:

a) Permeability: less than $10^{-9} \mathrm{~m} / \mathrm{s}$ (drained triaxial cell test) was specified according to [6]. However, this is unachievable by cementitious materials other than GGBS at the 28 and/or 90 days compliance curing periods according to earlier publication (CIRIA Special Publication SP106, 1996 cited in [6].

b) Strain at failure: value of $5 \%$ in a drained triaxial test. Yet, this is often difficult to achieve with the $10^{-9} \mathrm{~m} / \mathrm{s}$ permeability required especially at the 28 days compliance period [1, 6]. However, [6] and [21] argued that the $5 \%$ strain may be achieved in the drained triaxial, but only at effective confining pressures higher than could be experienced in situ. ICE [19] quoted a range of 0.2-2\% strains at failure under unconfined compression.

c) Strength: there is argument on the values of compressive strengths. They may be specified at minimum or maximum value and they may be varied from 100 to $1000 \mathrm{kPa}$. As the cementitious content increased from 100 $\mathrm{kg} / \mathrm{m}^{3}$ to $350 \mathrm{~kg} / \mathrm{m}^{3}$, the strength can be increased by a factor of 4 to 5 . However, the mix can be excessively thick and turned into hardened slurry that is strong but brittle [6]

\section{MATERIALS AND METHODS}

\subsection{Materials}

CB slurries are prepared from water $\left(\mathrm{H}_{2} \mathrm{O}\right)$. Pure water free of impurities produced through reversed osmosis at the Civil Engineering laboratory of the University of Birmingham was used in this study.

Sodium bentonite and two cementitious materials (PC and GGBS) (Figure 1) formed the CB mix. The PC was supplied by CEMEX UK. The brand, Rugby was described as CEM II type I Portland-fly ash cement in accordance with BS EN 197-1 - CEM Il/B-V 32,5 N. The GGBS has a fineness of approximately $500 \mathrm{~m}^{2} / \mathrm{kg}$ and contains oxides of calcium, silicon, aluminium, and magnesium as reported by the supplier (Heidelberg Cement Group, Civil and Marine Limited, UK). Test for percentage composition was not carried out as it is beyond the scope of this study.

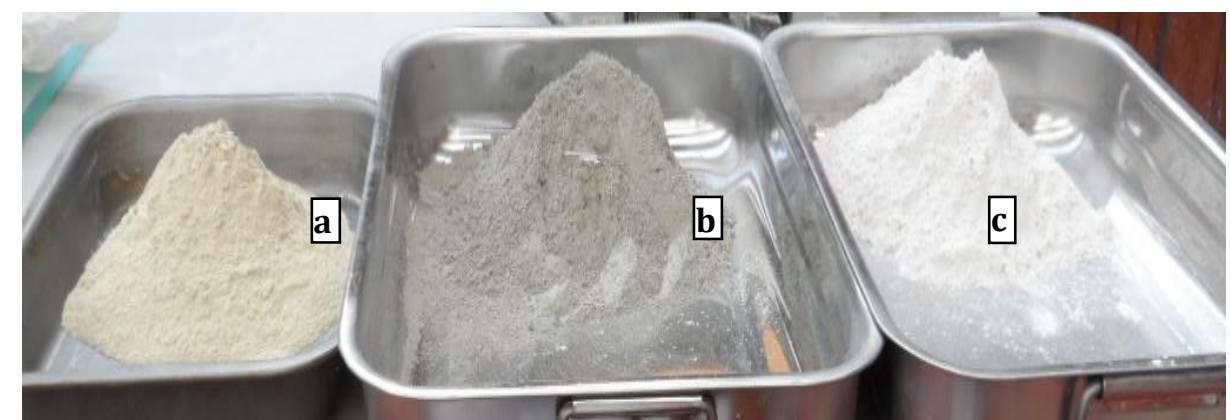

Figure 1 Mix materials: (a) Na-bentonite clay (b) PC (c) GGBS

\subsection{Mix-Design and Procedures}

Two mixes were investigated. Mix-design 1 following suggestion by [6], and Mix-design 2 (Table 1). The novel mix-design 2 was developed with 95\% GGBS in a $20 \%$ cementitious component, which is above the threshold recommended by [6], in order to further reduce cost of construction of CB slurry walls based on reducing the PC content. 
Table 1 A comparison of CB mix-design 1 (adopted from [6]) and CB mix-design 2 (applied in this study).

\begin{tabular}{|c|c|c|}
\hline Material & Quantity by mass $(\mathrm{g})$ & Percentage (\%) \\
\hline Water & 1000 & \\
\hline Na-Bentonite clay & 40 & 4 (by mass of water) \\
\hline $\begin{array}{l}\text { Cementitious material } \\
\text { (GGBS and PC) }\end{array}$ & 200 & 20 (by mass of water) \\
\hline \multicolumn{3}{|c|}{$\mathrm{CB}-$ mix-design 1} \\
\hline $\begin{array}{l}\text { GGBS } \\
\text { PC }\end{array}$ & $\begin{array}{l}160 \\
40\end{array}$ & $\begin{array}{l}80 \text { (by mass of cementitious material). } \\
20 \text { (by mass of cementitious material). }\end{array}$ \\
\hline \multicolumn{3}{|c|}{$\mathrm{CB}-$ mix-design 2} \\
\hline $\begin{array}{l}\text { GGBS } \\
\text { PC }\end{array}$ & $\begin{array}{l}190 \\
10\end{array}$ & $\begin{array}{l}95 \text { (by mass of cementitious material). } \\
5 \text { (by mass of cementitious material). }\end{array}$ \\
\hline
\end{tabular}

Mixing procedures followed methods used by [2] and [6] as follows: the bentonite clay was mixed with purified water for about 30 minutes using a low-shear power tool food mixer, then covered and left to hydrate for a period of 23 to 25 hours at room temperature. Thereafter, cementitious component was added in a dry powder form and mixed for a further 5 to 10 minutes while monitoring smoothness and homogeneity of the slurry. Where necessary, an additional mixing time was allowed to achieve consistency. When this was achieved, the slurry was then poured into bottom sealed sample tubes (plastic cylindrical moulds of 50 and $150 \mathrm{~mm}$ diameter and length, respectively) placed on a vibrating table (to reduce air entrapment in sample). Then top of sample tubes were sealed with flexible plastics and 'O-rings' and were allowed to set.

\subsection{Curing and Test Specimen Preparation}

Curing was assumed to begin when the mix was poured into the sample tubes and sealed. A period of 3 to 7 days was allowed for initial hardening or set (Figure 2a) and then samples were extruded (Figure 2b) and preserved (continued curing) under purified water in a bath (Figure $3 \mathrm{a}$ ) placed in a constant temperature $\left(18^{\circ} \mathrm{C}\right)$ room to minimize the impact of temperature. According to [4], the rate of this reaction decreases with falling temperature and completely stops at $-10^{\circ} \mathrm{C}$.

After each curing time $(7,14,28,60$ or 90 days), samples were cut to the desired testing length (100 mm) with the use of fine saw, pallet knife, cutting board and a split mould (100 and $50 \mathrm{~mm}$ length and diameter, respectively) (Figure 3b). This is referred to as 'cast and trim' method, as against casting samples to the testing length, which may be reduced through bleeding. The cutting board and split mould were used to provide a flat platform and guide to produce samples with relatively smooth and flat surfaces.
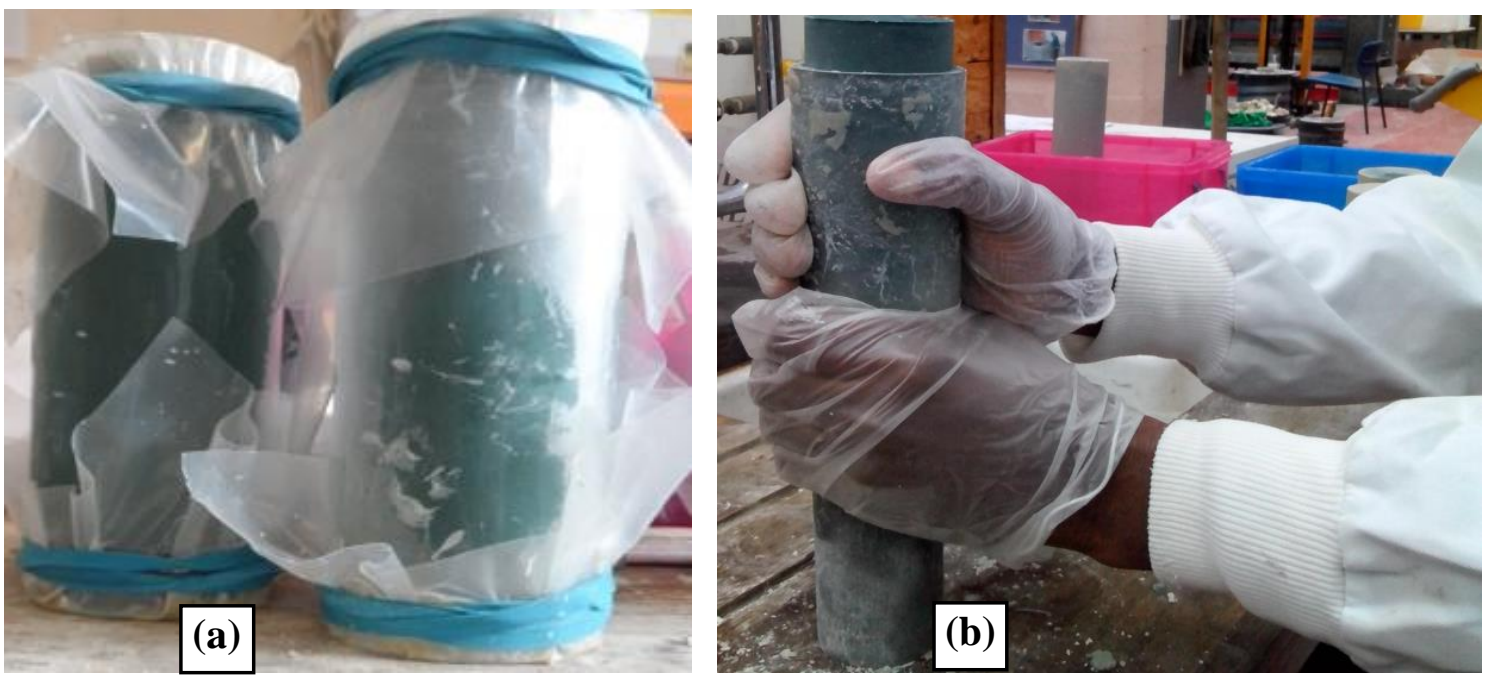

Figure 2 (a) samples cured in plastic moulds before extrusion, (b) sample extrusion 

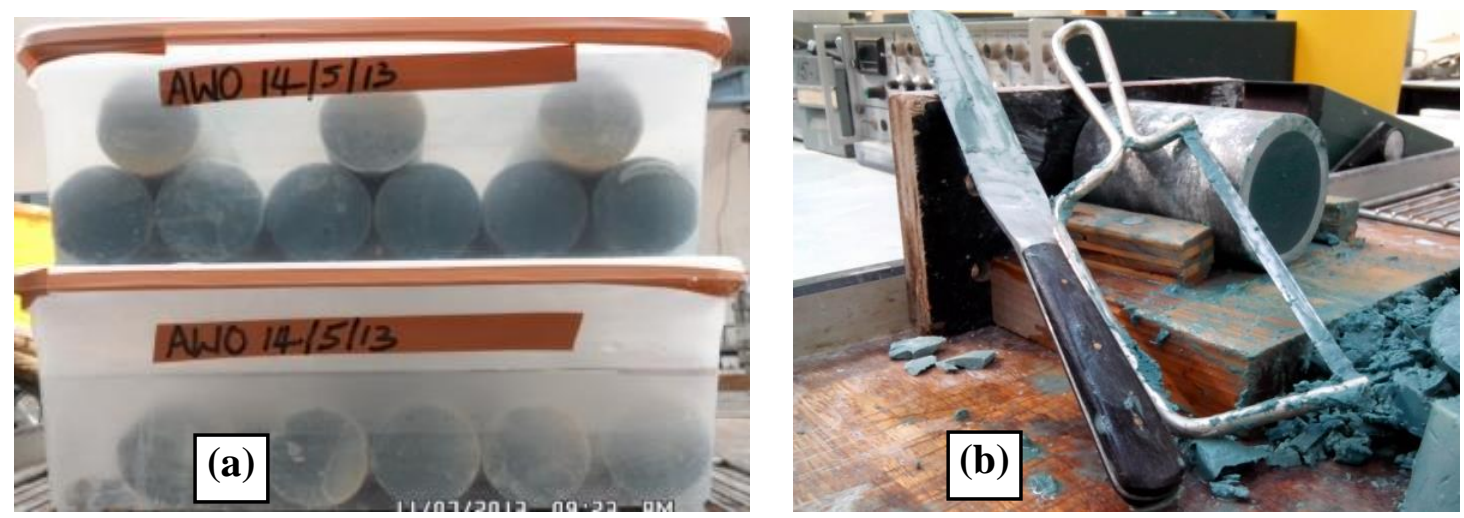

Figure 3 (a) samples curing under water; (b) cutting tools used for test specimen preparation

\subsection{Test Programme and Procedures}

A computerized compression equipment with $50 \mathrm{kN}$ loading ring capable of performing both confined and unconfined compressive tests under different setups, was used for this study. Figure 4 (a and b) shows the setups. Both setups were connected to an automatic data acquisition system (Figure 5) for easy and effective data logging.

Although for slurry barrier walls, unconfined conditions do not mostly exist, but it is important to carry out UCS test to determine repeatability [3]. Also, UCS shows more closely the actual strength of the wall under rapid loading assuming confining pressures available are very small. Therefore, UCS and unconsolidated undrained triaxial (UUT) tests were conducted in accordance with both [22 - 23], and [24], respectively. Specimens were tested under variable confining pressures (i.e., 50 - $200 \mathrm{kPa}$ ) in the UUT.

Prepared test specimens were weighed before testing. During testing, axial compression was allowed to progress beyond the yield point of specimen, to observe post-failure behaviour. After testing, a snapshot of failure mode was taken and then tested specimen was weighed, oven dried at temperatures between 105 and $110{ }^{\circ} \mathrm{C}$ for 24 hours and reweighed to determine its moisture content (in accordance with [25]). Three specimens were tested for each confining pressure and results averaged; but in few cases only results of two of the three tests were acceptable due to a far variation of the third. "Averaging method" has also been adopted by [1], [2] and [20].
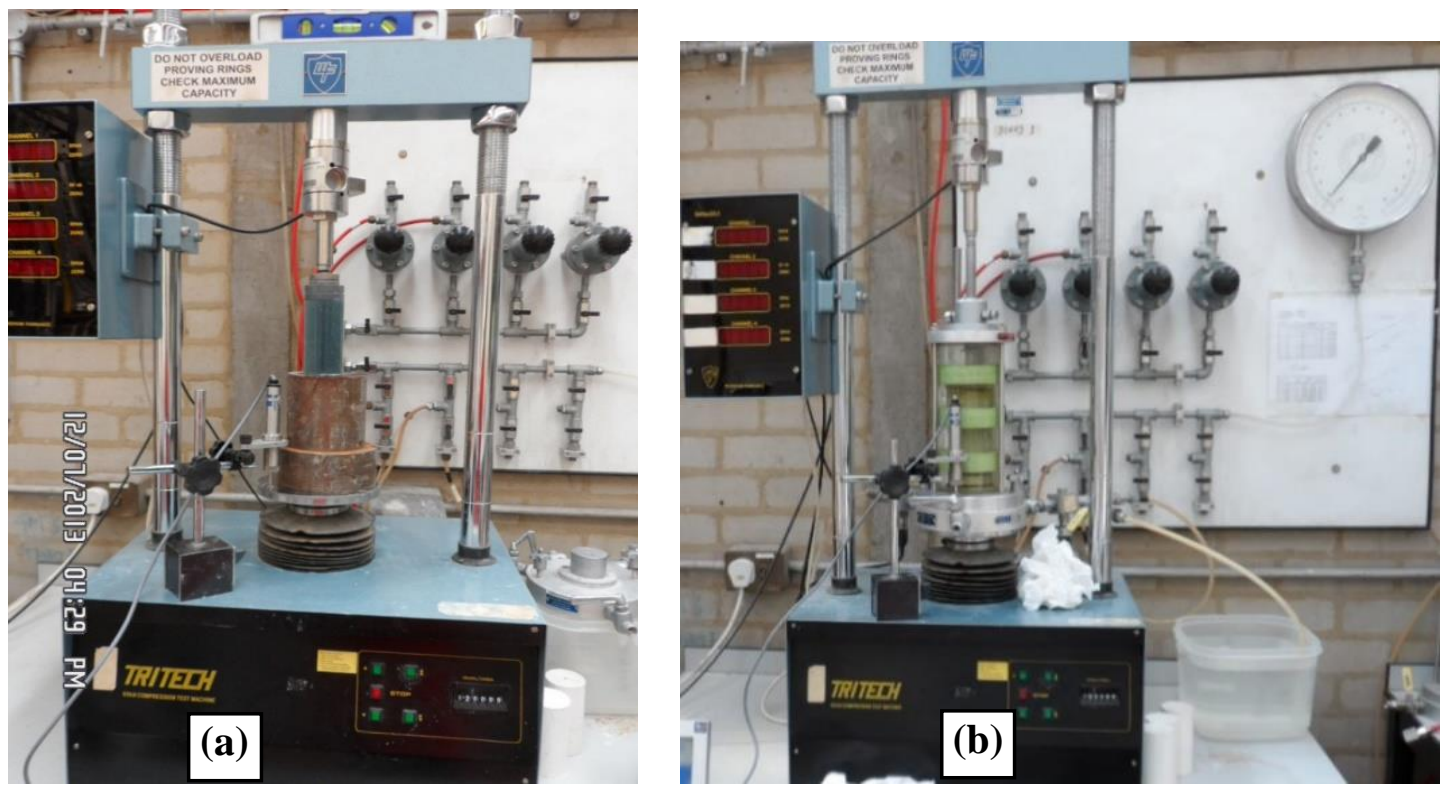

Figure 4 (a) UCS test load frame set-up, (b) triaxial test apparatus set-up 


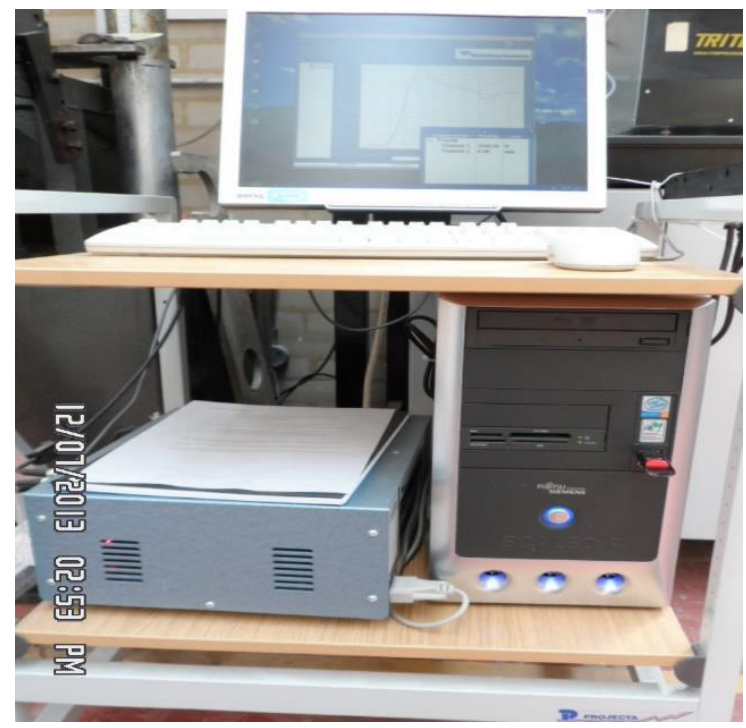

Figure 5 Data acquisition system attached to test apparatus

Specimens prepared from mix-design (1) (Table 1) were investigated on each of the specified curing days $(7,14$, 28, 60 and 90) while specimens from mix-design 2 (Table 1) could only be tested at 7, 14 and 28 days due to time constraints.

\subsection{Validation of Experimental Method}

For the purposes of accuracy and understanding of machines (particularly the compression equipment), preliminary calibration tests have been carried out on rubber specimens and on preliminary CB specimens. From previous knowledge, rubber samples were expected to produce linear graphs (force versus strain). This, however, was obtained in the preliminary UCS tests but an irregular trend was observed at the early stages of confined triaxial tests conducted. More than three rubber samples were tested at different confining pressures and all of them showed similar irregularities at strains ranging from 0.1 to $0.5 \%$. It was suggested at this point that, the piston within the triaxial cell may be aligning itself with the piston on the load frame at the early stage of compression. Thus, a corresponding strain was subtracted where this trend was noticed in the main testing.

As mentioned, the averaging method was adopted previously [1-2, 20]. That is, at least three samples were tested at every data point and the results checked for repeatability then those with good repeatability are averaged. This method was employed in this study as CB slurry samples showed different behaviours resulting from inconsistencies in their preparation. Repeatability was highly concentrated on the strain at failure levels of the three samples. Where a good repeatability occurred in only two of the three samples, the third one was rejected.

\section{RESULTS AND DISCUSSION}

\subsection{Volume, density and moisture content}

All test specimens were prepared to the same dimension (100 $\mathrm{mm}$ and $50 \mathrm{~mm}$ length and diameter, respectively) before any testing was carried out. Volume, therefore, was $1.96 \times 10^{-2} \mathrm{~cm}^{3}$ and remained constant throughout testing since unconsolidated undrained tests do not result in volume change. However, density and moisture content vary as they depended also on other properties.

Density depends on volume and mass of specimen. The mass of specimens varied slightly, even for specimens of the same mix and curing time. The average results of moisture content and density determined in accordance with [26] (Figures 6 and 7, respectively).

While specimens from mix-design 2 (95\% GGBS) showed a decrease in moisture content with curing time, those from mix-design 1 (80\% GGBS) displayed an inconsistent trend. Nevertheless, mix-design 1 appeared to produce more consistent specimens at each curing time, following that its representative specimens for each curing period exhibited very little variations in moisture content, whereas, their counterparts from the mix-design 2 had wider variations in moisture content. However, moisture content did not show a well-defined relationship with both peak-deviator stress and strain at failure, for both mixes.

In Figure 7, specimens from both mix-designs exhibited similar behaviour with respect to density change with curing time. There was an initial increase from 7 to 14 days and then it began to decrease towards 60 days and again 
increases towards 90 days. The density for initial CB slurry is usually specified between the range of 1.040 to 1.150 $\mathrm{Mg} / \mathrm{m}^{3}$ and a threshold of $1.300 \mathrm{Mg} / \mathrm{m}^{3}$ at end of construction since it is a property for the stability of trench wall [3]. This could imply that density is mostly important at the construction stage of CB slurry walls. In this study initial density was not determined but estimates on the testing days revealed values ranging between 1.134 to $1.162 \mathrm{Mg} / \mathrm{m}^{3}$ for mixdesign 1 (80\% GGBS) and 1.133 to $1.147 \mathrm{Mg} / \mathrm{m}^{3}$ for mix-design 2 (95\% GGBS). The results fall within the recommendation of [3], that density may rise from 1.040 to $1.250 \mathrm{Mg} / \mathrm{m}^{3}$ immediately after construction.

Figure 7 reveals that mix-design 1 was denser than mix-design 2. Two reason may be suggestive for the density variations in the two mix-designs: PC being denser than GGBS and/or higher proportions of GGBS in the mix-design 2 might cause higher air entrainment in specimens. Air bubbles entrapped in slurry barrier walls could undesirably increase permeability.

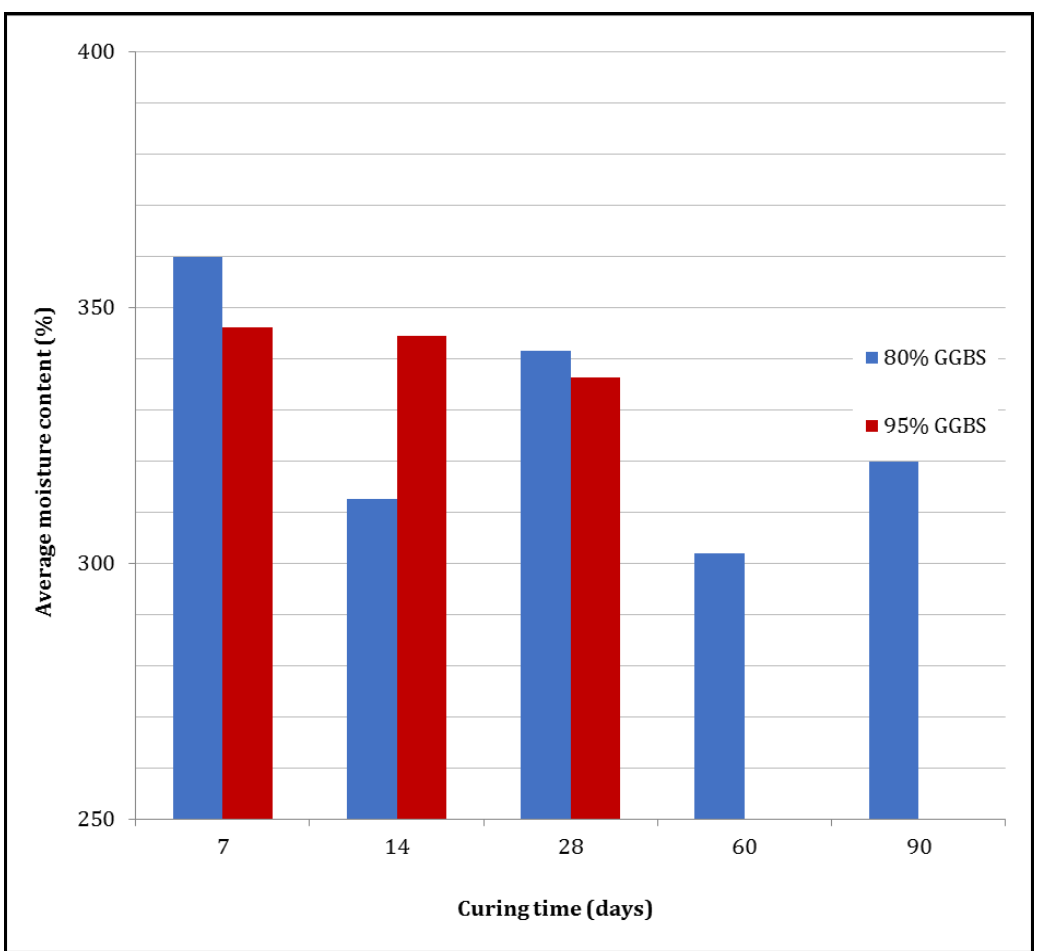

Figure 6 Effect of curing time on moisture content 


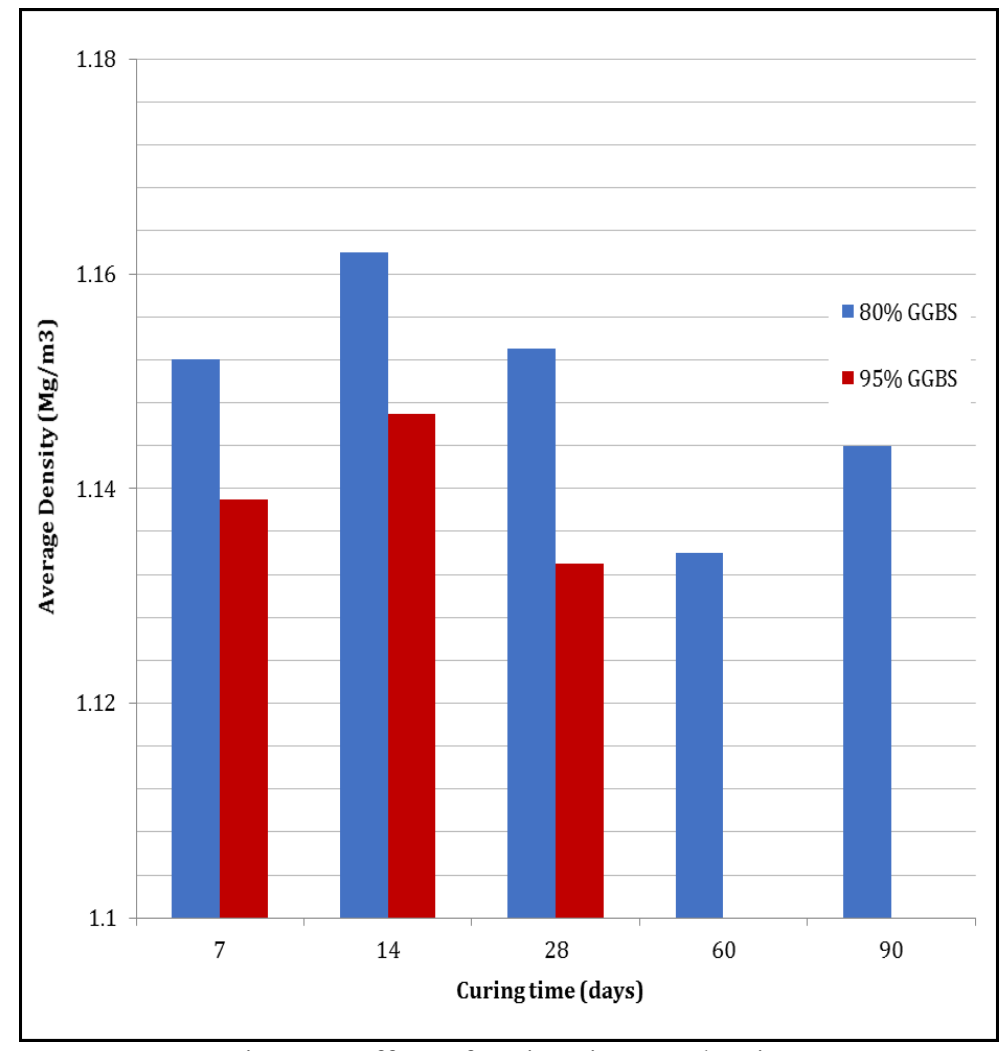

Figure 7 Effect of curing time on density

\subsection{Unconfined Compressive Strength}

Following an initial comparison of two rates of deformation $(1.2 \mathrm{~mm} / \mathrm{min}$ and $1.0 \mathrm{~mm} / \mathrm{min})$ carried out here, to observe behavioural change due to varying rate of deformation, has shown (Figure 8) little but insignificant difference in the stress-strain behaviour of specimens; with the $1.0 \mathrm{~mm} / \mathrm{min}$ giving the higher deviator stresses. Royal et al. [1] have also compared 1.0 and $1.3 \mathrm{~mm} / \mathrm{min}$ rates of deformation in a UCS test investigating CB samples containing PFA. The results also revealed an insignificant impact of those rates of deformation.

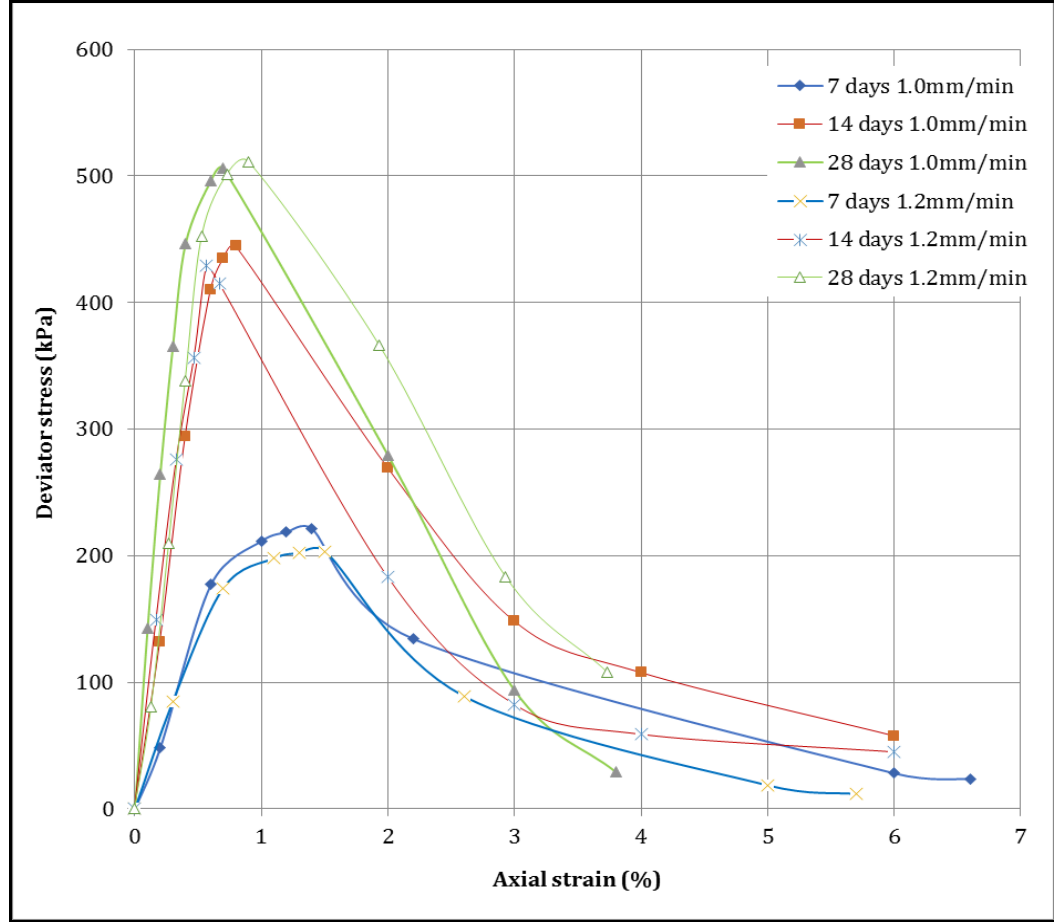

Figure 8 Effect of rate of deformation on UCS for samples with $80 \%$ GGBS 
Consequently, further testing of both mix-designs 1 (80\% GGBS) and 2 (95\% GGBS) was conducted using a rate of deformation of $1.2 \mathrm{~mm} / \mathrm{min}$. Figure 9 and Figure 10 present their stress-strain behaviour and shear strength estimated from Mohr's circles, respectively under the unconfined compression test.

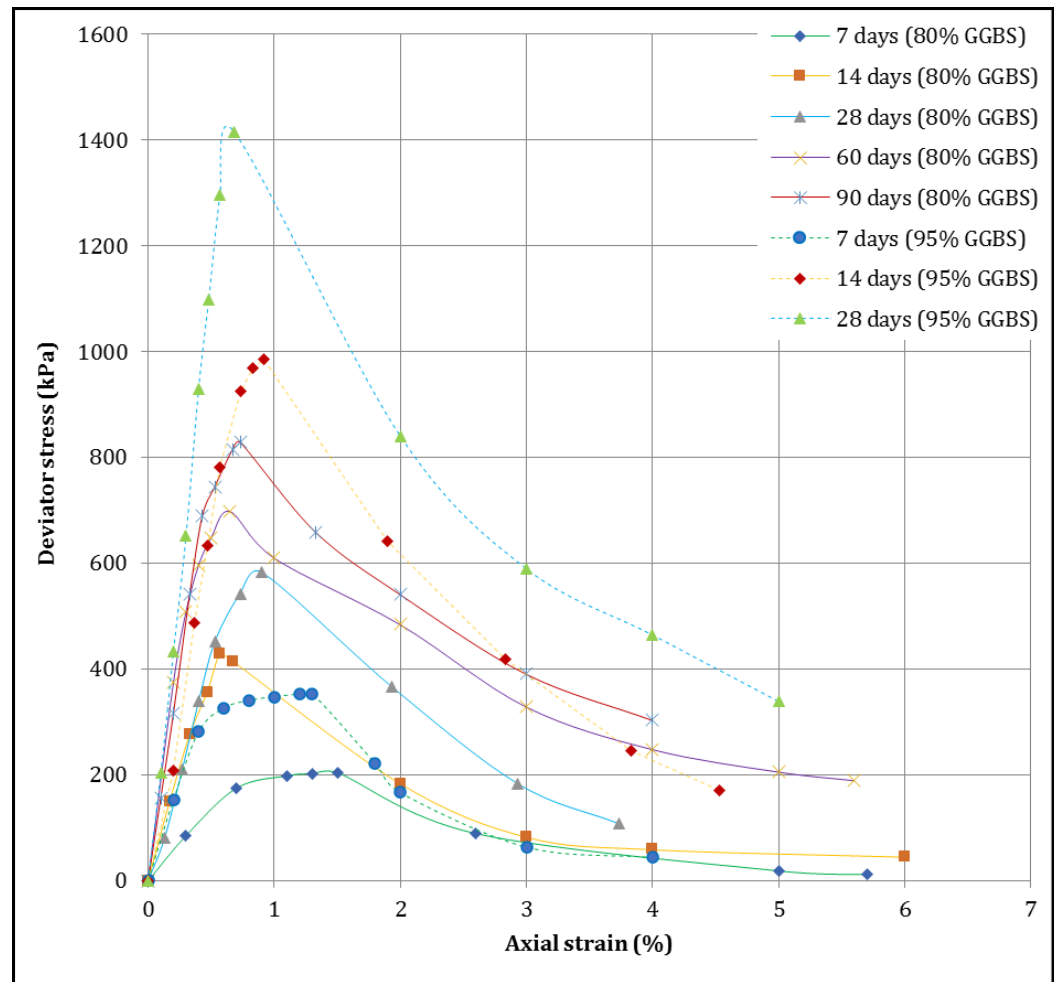

Figure 9 Unconfined compressive behavior of samples

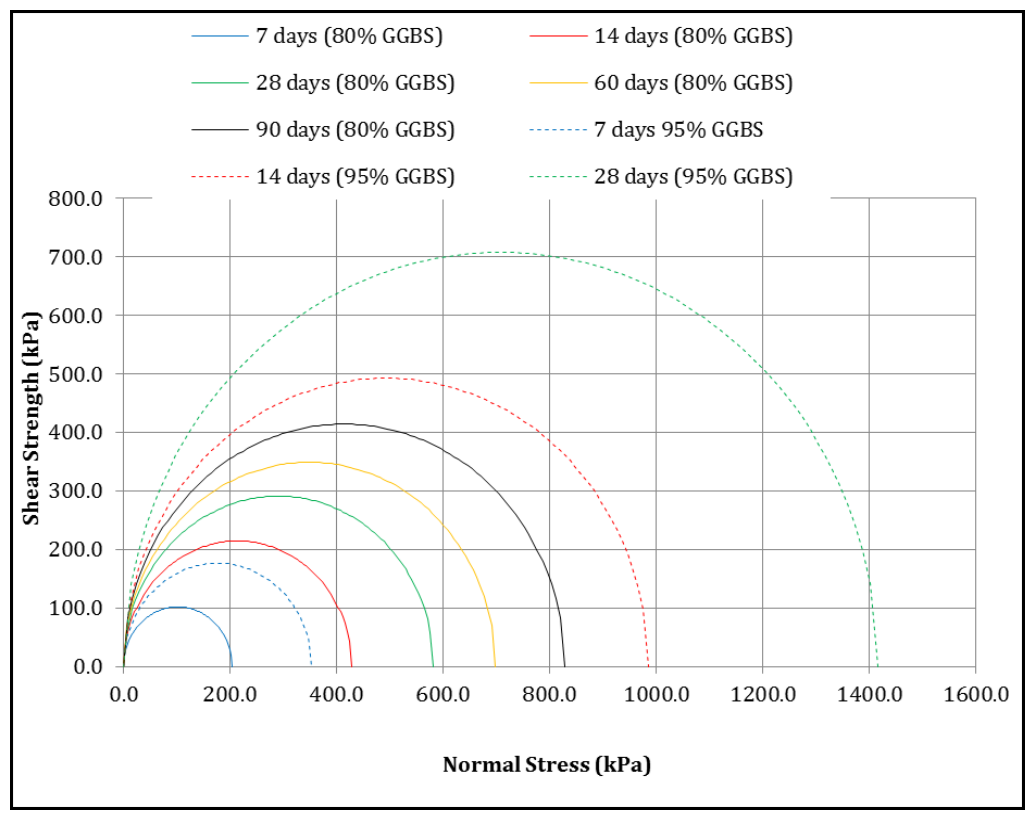

Figure 10 Mohr's circles under unconfined testing

Figure 9 shows increase in UCS with curing time for both mixes, but more significantly with mix-design 2. Peakdeviator stresses range from 203.44 at 7 days to only $828.26 \mathrm{kPa}$ at 90 days curing for mix-design 1 while it was between 353.21 at 7 days to $1416 \mathrm{kPa}$ at curing period of 28 days for mix-design 2. The Mohr's circles in Figure 10 indicate shear strengths estimates generally in excess of the minimum $100 \mathrm{kPa}$ stress suggested for compliance test at 28 and 90 days.

Specimens from mix-design 1 showed an initial strength growth of approximately $100 \%$ at early age (i.e., from 7 14 days curing), about $40 \%$ increase from 14 - 28 days, and nearly $20 \%$ further increase both from 28 - 60 and 60 - 90 days. For specimens of mix-design 2, the early strength increase was very rapid. Over $270 \%$ from 7 - 14 days curing, but the subsequent strength growth was only about $44 \%$ from 14 - 28 days curing period. Though testing of mix-design 2 was 
only done at a maximum of 28 days curing, the trend of strength development tends to support that of the mix-design 1 at the 28 days curing period.

While 28 days is commonly specified as compliance curing period for PC products as it matches an 'almost complete' hydration period for alite (whose hydration products give hardened cement its strength) [4], the results in Figure 9 indicate further strength development beyond this period. Nevertheless, it is obvious that the most significant strength for the both CB mixes only developed at early curing times up to 28 days. High quantities of calcium silicates are known to enhance the development of strength in cement mixes because of its positive effect in hydration reaction. This suggests why mix-design 2, having higher GGBS, thus, higher calcium silicates exhibited higher strengths than mixdesign 1.

On the other hand, high quantities of calcium silicates may inhibit the effectiveness of bentonite [7], thereby compromising the permeability and ductility of the CB wall. Although permeability was not considered in this study, Figure 11 shows the effect of the quantity of GGBS on stiffness of both mix-designs. Mix-design 2 (95\% GGBS) exhibited rapid stiffening with curing time up to the maximum 28 days. However, its counterpart with $80 \%$ GGBS only appearing to rapidly stiffen at early age, had generally shown a very gentle increase in stiffness at later ages and almost levelling out between 60 - 90 days curing. It is evident here that increased proportions of GGBS in CB slurry walls increases its brittleness than may be required if the $5 \%$ strain specification was to be achieved.

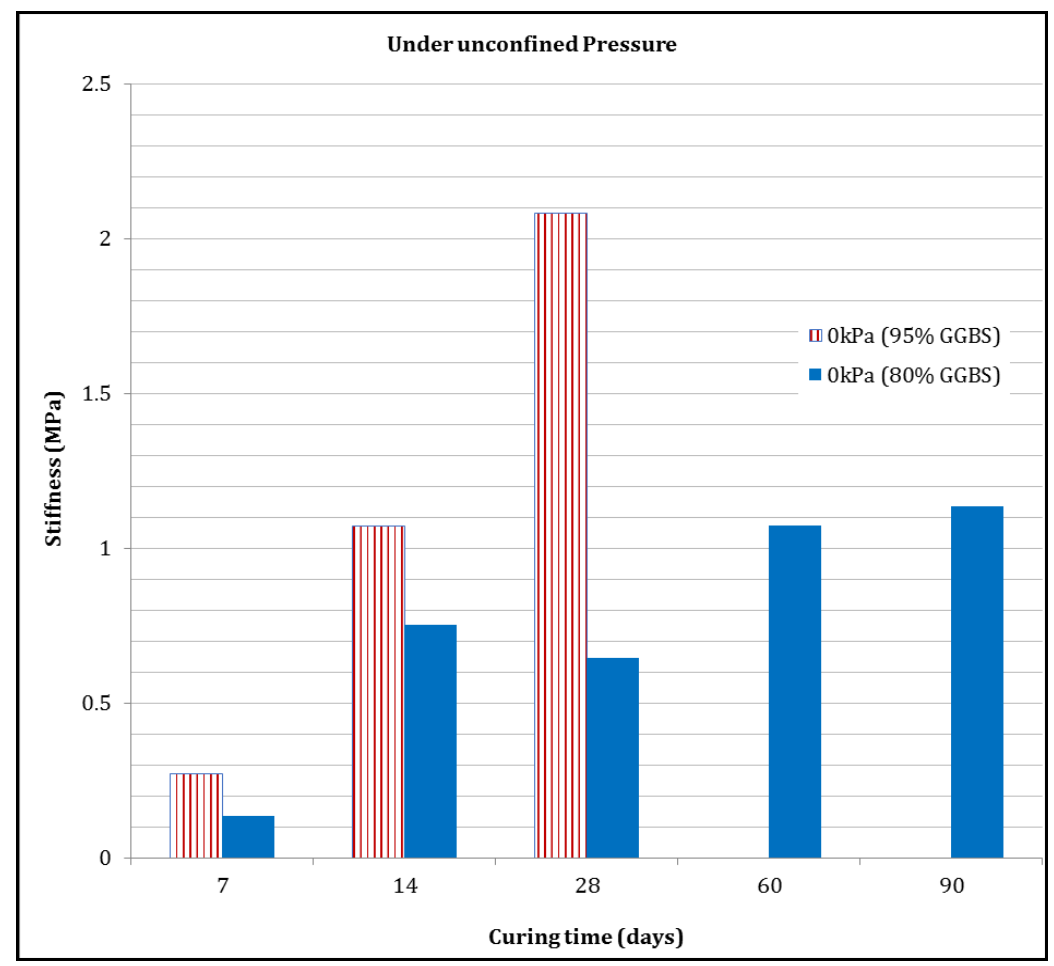

Figure 11 Effect of curring time on stiffness

In this study, strains at failure under the UCS test for both mix-designs range between 0.65 to $1.5 \%$. Though these values did not meet the 5\% specification, it is important to note that the value is only required for a drained triaxial test. Jefferis [14] and [19] have reported findings of strain at failure similar to those in the present study. However, in contrast to findings by [2], here, higher strains at failure generally corresponded to the higher proportions of GGBS.

Although a decrease in strain at failure corresponded to increased strength for mix-design 2, this was not the case for mix-design 1 . The reason for the lack of a defined correlation between strength and strain at failure for mix-design 1 remains unclear. For both mixes, specimens cured for 7 days behaved in a ductile manner akin to a 'non-sensitive' soil [27] under loading. An initial increase of the deviator stress resulted in straining, but towards the failure stress the deviator stress tends to level out. Though there was a peak-deviator stress, it was not significantly greater than the stress at failure.

On the other hand, specimens cured 14, 28, 60 or 90 days showed brittle stress-strain behaviour similar to that of a 'sensitive' soil [27] where a peak-deviator stress obviously develops, after which the sample experiences a rapid strain softening. All specimens tested under the UCS exhibited similar behaviour post-failure with deviator stress nearly reaching zero; an indication that after cementing bond is broken, CB samples under the UCS, have little or no frictional interaction.

A similar study was conducted by [2] on CB mixes containing 10, 15 and $20 \%$ cementitious materials (by mass of bentonite water) cured for 1 month. 0, 20, 40,60, 70, 80 and $90 \%$ of the cement was GGBS in the three mixes. Their 
investigation revealed that at GGBS levels less than 70\%, there was an insignificant variation in UCS values, above which significant variations were witnessed. This may support the variations in UCS values recorded in the current two mix-designs. Nevertheless, identical mixes in the two studies (20\% cementitious material with $80 \%$ GGBS) investigated after curing for 28 days, have failed to produce comparable maximum UCS values. Opdyke and Evans [2] reported 356 $\mathrm{kPa}$ contrary to $582 \mathrm{kPa}$ reported here.

\subsection{Confined undrained behaviour}

Usually, CB slurry walls experience confining pressures of various degrees and in the short term respond in an undrained manner to rapidly imposed stresses due to its low permeability. Short term shear strength becomes an important criterion for CB slurry walls. UUT tests were carried out on the two samples as stated in section 2.4 using a rate of deformation of $1.2 \mathrm{~mm} / \mathrm{min}$ at variable confining pressures (i.e., $50-200 \mathrm{kPa}$ ). The relationships obtained (Figure $12 \mathrm{a}, \mathrm{b}$, and c) are discussed below.

Figure 12 ( $\mathrm{a}, \mathrm{b}$ and $\mathrm{c}$ ) show that deviator stress increases with curing time for both mix-designs. The percentage increases with curing time which are akin to those experienced under the UCS may have been due to similar reasons discussed in that section (4.2).

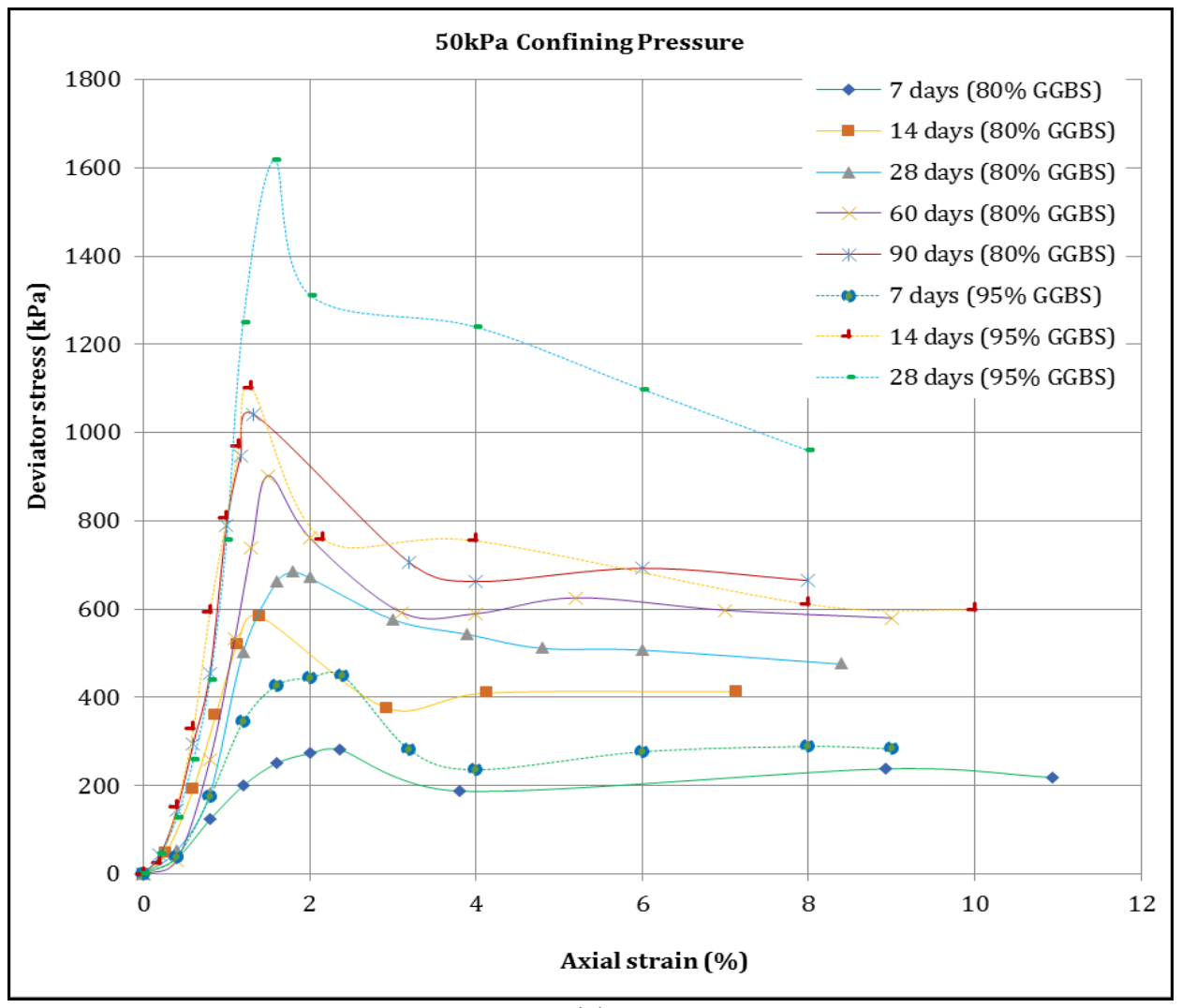

(a) 


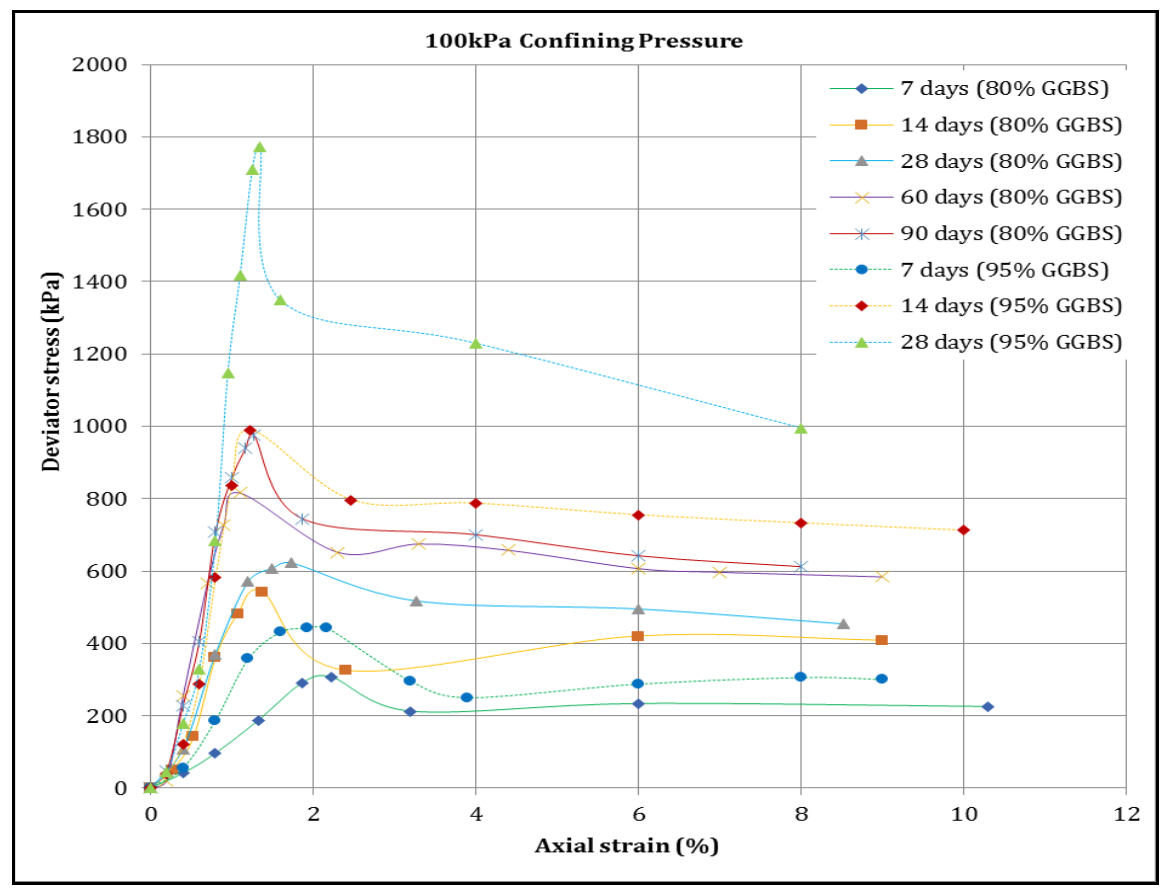

(b)

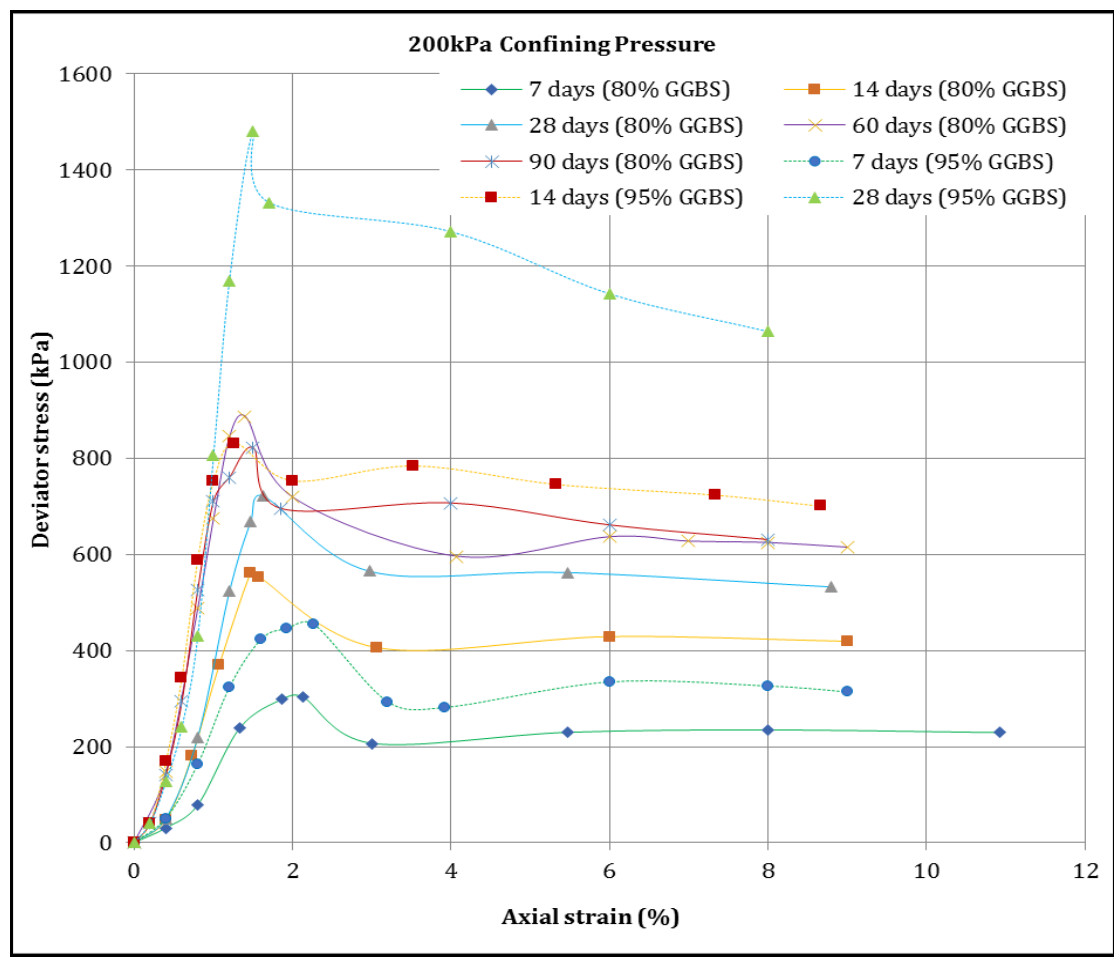

(c)

Figure 12 Samples behavior under the UUT at different confining pressures; (a) $50 \mathrm{kPa}$ (b) $100 \mathrm{kPa}$ and (c) $200 \mathrm{kPa}$

From the Figure 12 (a, b, and c), it can be seen that after the initial stress reduction (i.e., strain softening) post failure, a relatively constant stress was maintained, as opposed to what obtained under the UCS. This was suggested to be the effect of confinement and to a less extent, friction between the CB particles. This may be true when comparing these post-failure behaviours with their counterparts under unconfined conditions presented in Figure 9. Both undrained shear and post-failure strengths were seen to be greater with mix-design 2, suggestive that strength enhancement in the CB mixes was largely dependent on proportion of GGBS rather than that of PC. Nevertheless, GGBS, a pozzolan, is only cementitious inclusive portlandite (calcium hydroxide) provided by the hydration of PC.

Generally, the application of confining pressure significantly improves the strain at peak-deviator stress (Figure 13a), but peak-deviator stress is merely slightly greater than those obtained without confining pressure (Figure 13b). 
Consequently, shear strength has also not been much influenced by confining pressure as can be seen in Figure 14 (a and b).

However, from Figure 13 ( $\mathrm{a}$ and $\mathrm{b}$ ), a change of confining pressure in the range of $50-200 \mathrm{kPa}$ did not appear to clearly impact on deviator stress at its peak. That is, for CB walls, the degree of confinement they experience can be of little or no consequence on their undrained behaviour.

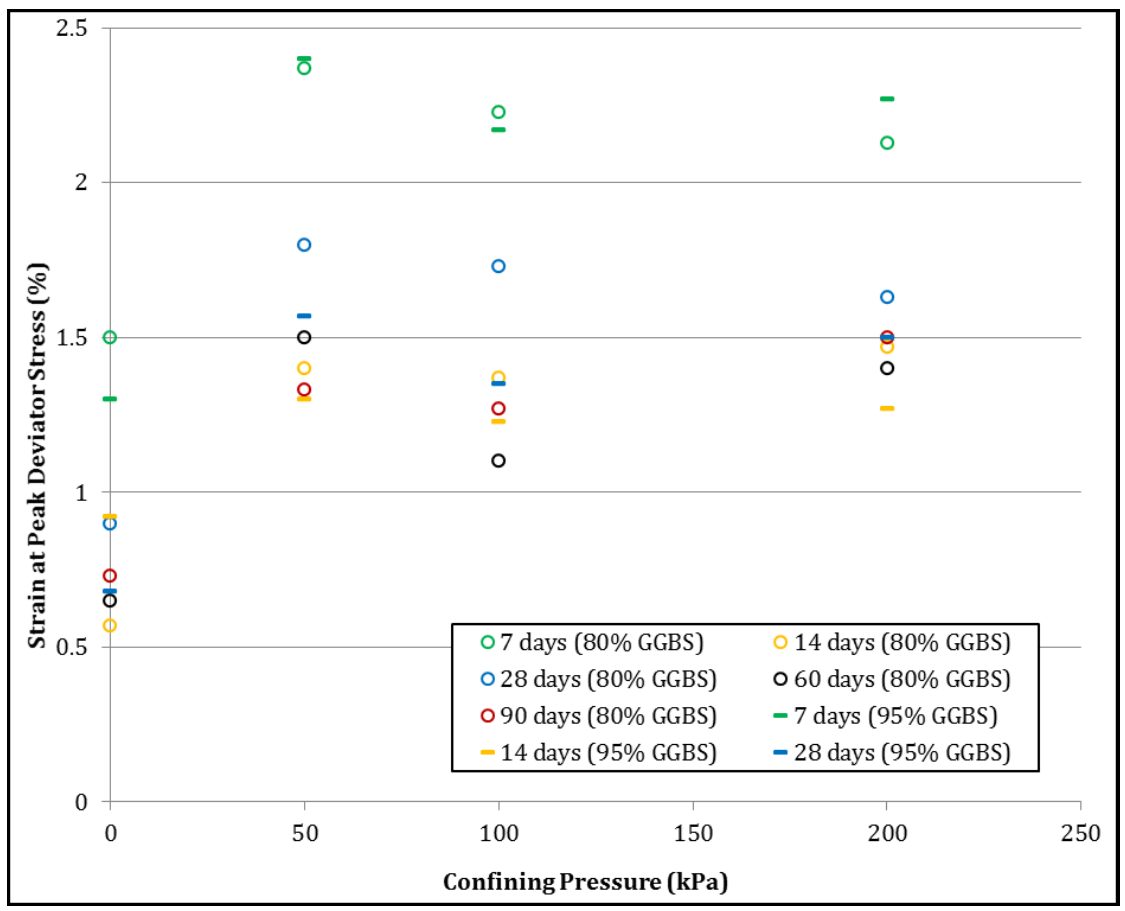

(a)

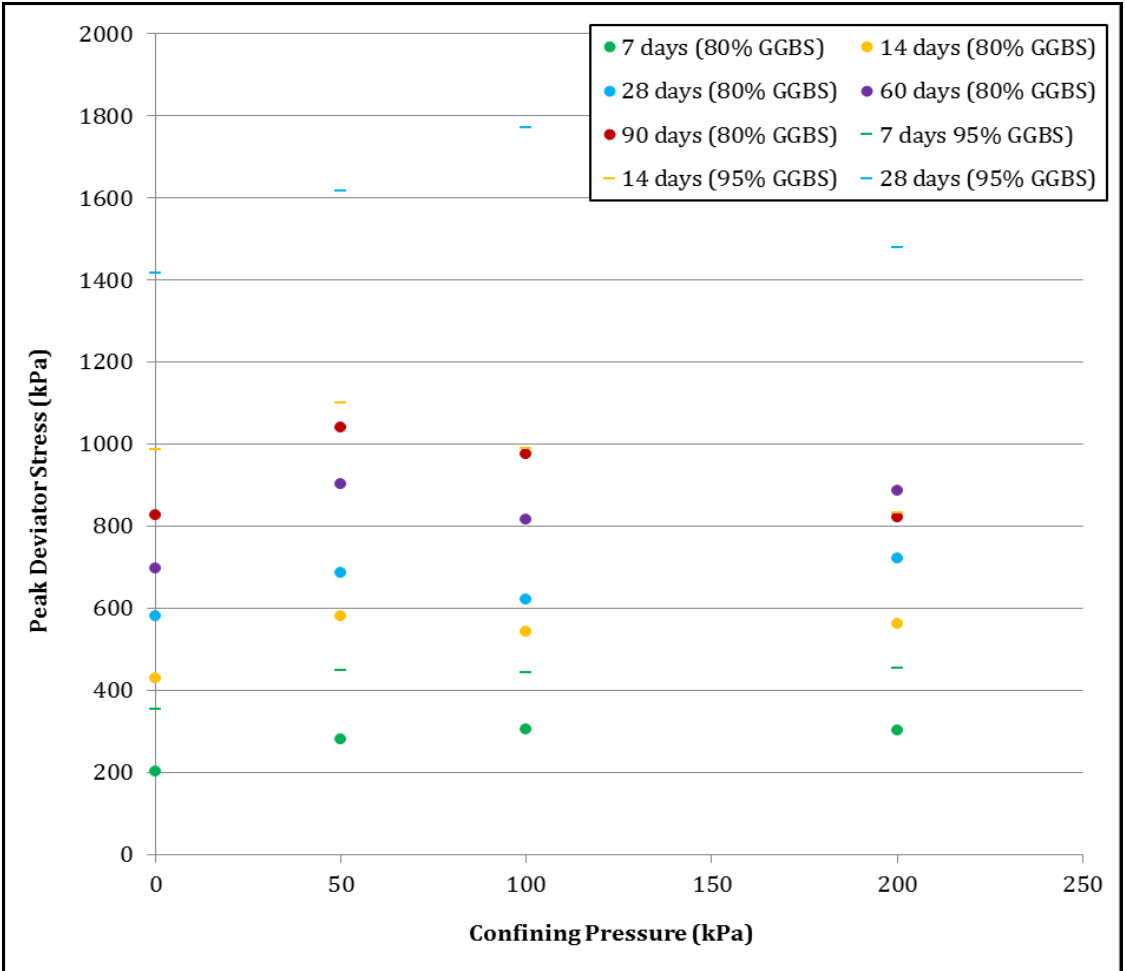

(b)

Figure 13 Impact of confining pressure on; (a) strain at peak-deviator stress (b) peak-deviator stress 


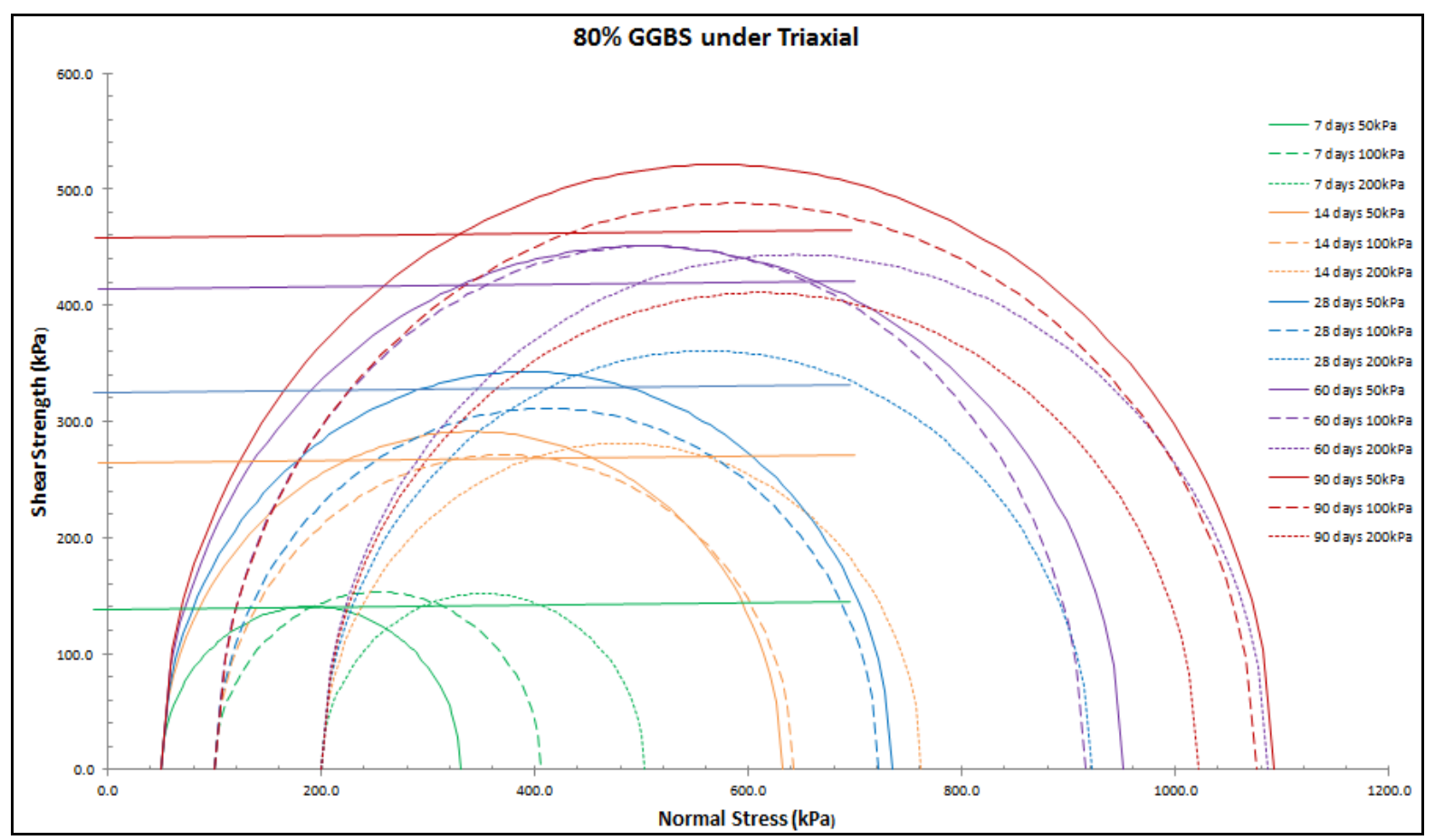

(a)

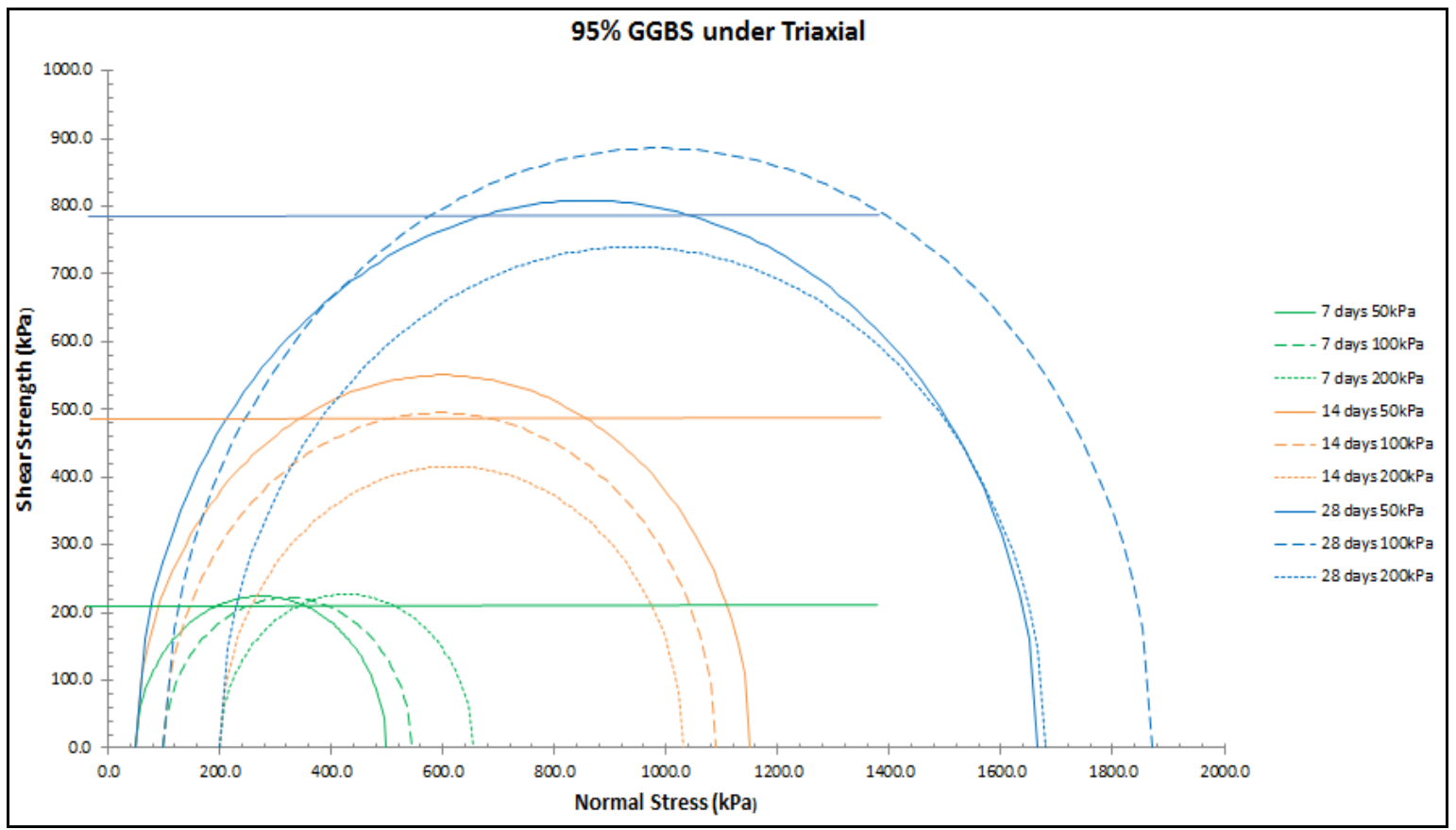

(b)

Figure 14 Mohr's circles obtained from the UUT at variable confining pressures $(50,100$, and $200 \mathrm{kPa}$; (a) for mixdesign 1 (80\% GGBS) and (b) for mix-design 2 (95\% GGBS)

Peak-deviator stresses under the UUT range from 280 to $1041 \mathrm{kPa}$ for mix-design 1 and 443 to $1771 \mathrm{kPa}$ for mixdesign 2. On the other hand, strains at failure range from 1.1 to $2.37 \%$ and 1.20 to $2.4 \%$ for mix-designs 1 and 2 , respectively. Although it may be argued since only two different mixes were investigated here, the results presented in Figure 13a, obviously show that strain at failure may not be significantly influenced by the proportion of GGBS at the early age of a $\mathrm{CB}$, especially under confining pressures.

The Figure 13a reveals that higher strains at failure were prominent at 7 days curing for both mixes. This was not surprising considering that younger specimens would have undergone lesser hardening making them more ductile than older specimens.

The Mohr's circles (Figure $14 \mathrm{a}$ and b) indicate a higher shear strength corresponding to older specimens. This also may not be surprising because the older the specimen the more hardened it is expected. However, in a field 
condition, it is possible that older samples haven undergo ageing conditions may become weaker than their younger counterparts. Though, there is little agreement on what specific strength is required for CB walls [6], both mix-designs investigated here, exhibited undrained shear strengths within and above the range (100 to $1000 \mathrm{kPa})$ recommended according to [6].

Under confining pressures, the stress-strain behaviour of mix-design 1 cured 7 and 28 days as well as mix-design 2 cured 7 days showed behaviours akin to the 7 days samples tested under the UCS presented in section 4.2. That is, the peak-deviator stress is not significantly greater than the stress at failure while specimens from mix-design 1 cured 14,60 and 90 days and specimens from mix-design 2 cured 14 and 28 days also behaved like those of similar ages tested under the UCS, exhibiting an obvious peak-deviator stress, which is a kind of brittle failure.

Like many previous studies unable to achieve the standard specification of 5\% strain for CB walls under drained triaxial, it was rather more difficult to achieve that here since samples were merely subjected to undrained conditions. The undrained behaviour suggests that specimens from the two mix-designs studied here, became brittle from 14 days curing upwards as they attain less than $2 \%$ strain pre-failure.

Although a clear relationship was not observed (Figure 15) between stiffness and confining pressure, stiffness, however, tends to increase with curing time for both mixes. The Figure 15 also reveals that higher proportions of GGBS enhance stiffness. This is the same with results gotten under unconfined conditions. Increasing stiffness of CB slurry walls may not be a desired exercise as brittle $\mathrm{CB}$ walls would not attain the required strain level before developing cracks, that subsequently and potentially increase permeability of the barrier walls.

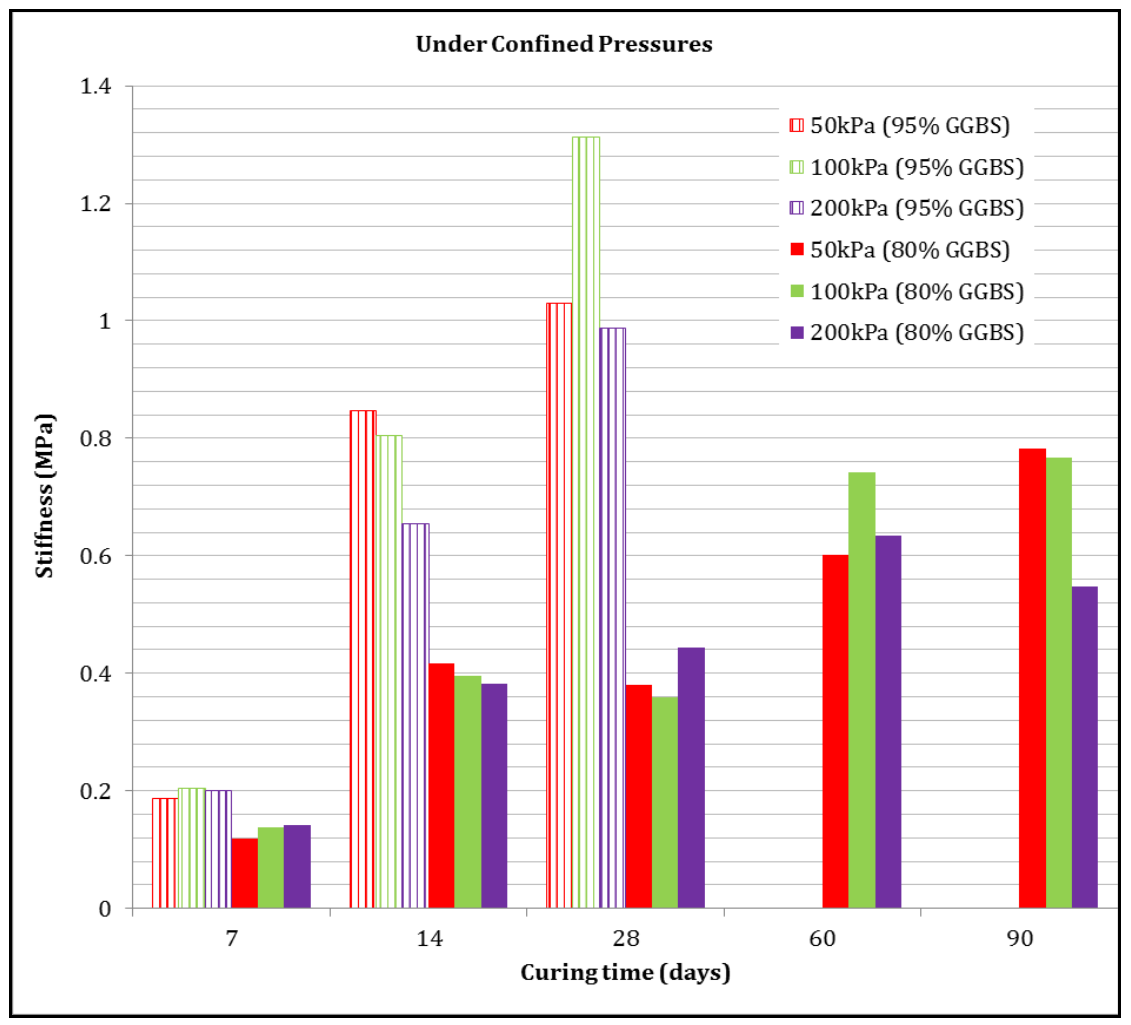

Figure 15 Effect of curring time on stiffness

\section{CONCLUSION}

This study focused on and compares the stress-strain behaviour of two different mix-designs of cementbentonite (CB) slurry wall under undrained conditions, in relation to factors such as curing time, confining pressure and proportion of ground granulated blast furnace slag (GGBS). The following conclusions were reached:

The two mix-designs show that increasing GGBS content enhances both shear strength and stiffness. However, the performance of the higher GGBS mix may be poorer in terms of the wall's flexibility, which may compromise permeability. A simple UCS should be sufficient to assess the strength of CB walls since confining pressures of 50, 100, and $200 \mathrm{kPa}$ (rarely experience in situ) did not significantly change the stress-strain properties of the CB investigated just as rate of deformation. Instead, curing time is suggested to be considered an important factor at the design stage, since it also controls the flexibility of the barrier wall. Depending on the life-span need of the CB barrier wall, a young flexible and economic barrier wall may suffice. Though the density of prepared liquid slurries was not considered, densities of the hardened slurries suggest that higher levels of GGBS in CB reduce density, which may enhance workability. 
It was not possible to carry out drained testing because of the time available for the study. This study suggests further work to establish a mix-design that will be economical in terms of the proportion of cementitious component. This suggestion is since the $20 \%$ presently used produces strength more than the $100 \mathrm{kPa}$ specified at 28 days compliance curing. Also, to establish a balance between adequate strength and adequate flexibility of CB barrier walls in order not to compromise permeability. Also, it is highly suggested to investigate other alternative pozzolanic industrial wastes rather GGBS to save resources, reduce the burden on the environment and reduce the cost.

\section{ACKNOWLEDGMENT}

The authors would like to acknowledge the Petroleum Technology Development Fund (PTDF), Nigeria for the scholarship awarded to the first author, by which this study was initiated.

\section{REFERENCES}

[1] Royal AC, Makhover Y, Moshirian S, Hesami D. Investigation of cement-bentonite slurry samples containing PFA in the UCS and triaxial apparatus. Geotechnical and Geological Engineering. 1;31(2):767-81, 2013.

[2] Opdyke SM, Evans JC. Slag-cement-bentonite slurry walls. Journal of geotechnical and geoenvironmental Engineering.131(6):673-81, 2005.

[3] Williams M, Ghataora GS. Effect of fibre reinforcement on the properties of ground granulated blast furnace slagcement-bentonite slurry. Studia Geotechnica et Mechanica. 1;33(4):63-83, 2011.

[4] Domone P, Illston J, editors. Construction materials: their nature and behaviour. CRC Press; 2010.

[5] EN BS. 206-1 Concrete-Part 1: Specification, performance, production and conformity. British Standards Institution, London, 2000.

[6] Garvin SL, Hayles CS. The chemical compatibility of cement-bentonite cut-off wall material. Construction and Building Materials. 1;13(6):329-41, 1999.

[7] Trivedi DP, Holmes RG, Brown D. Monitoring the in-situ performance of a cement/bentonite cut-off wall at a low level waste disposal site. Cement and concrete research. 1;22(2-3):339-49, 1992.

[8] Philip LK. An investigation into contaminant transport processes through single-phase cement-bentonite slurry walls. Engineering geology. 1;60(1-4):209-21, 2001.

[9] Egirani DE, Shehata N, Ugwu IM, Opukumo A. Experimental Studies on the Characterization of Niger Delta Smectite and its Performance as a Geochemical, Bacteriological, and Geotechnical Barrier System. Athens Journal of Sciences. 7(4):207-224, 2020.

[10] Ghazizadeh S, Bareither CA. Stress-controlled direct shear testing of geosynthetic clay liners II: Assessment of shear behavior. Geotextiles and Geomembranes. 1;46(5):667-77, 2018.

[11] Andrejkovičová S, Janotka I, Komadel P. Evaluation of geotechnical properties of bentonite from Lieskovec deposit, Slovakia. Applied Clay Science. 1;38(3-4):297-303, 2008.

[12] Owaidat LM, Andromalos KB, Sisley JL, Civil Engineer U. Construction of a soil-cement-bentonite slurry wall for a levee strengthening program: In Proceedings of the 1999 Annual Conference of the Association of State Dam Safety Officials, St. Louis, Mo pp.10-13, 1999.

[13] Oluwapelumi OO. Geotechnical characterization of some clayey soils for use as landfill liner. Journal of Applied Sciences and Environmental Management. 19(2):211-7, 2015.

[14] Jefferis S. Cement-bentonite slurry systems: In Grouting and Deep Mixing (pp. 1-24), 2012.

[15] Privett KD, Matthews S, Hodges R. Barriers, liners and cover systems for containment and control of land contamination. Construction Industry Research and Information Association; 1996.

[16] Xanthakos P.P. Slurry Walls, McGraw-Hill Company, New York, 1979.

[17] Jefferis SA. In-ground barriers. Contaminated land-problems and solutions. pp111-40, 1993.

[18] Hakan Ören A, Kul TÖ, Koç ME, Demirkıran H. Comparison of the Hydraulic Conductivity of GCLs with That of Bentonitic Mixtures: In Geo-Chicago 2016 (pp. 358-367), 2018.

[19] ICE (Institution of Civil Engineers). Specification for the construction of slurry trench cut-off walls as barriers to pollution migration. 1999.

[20] Royal AC, Opukumo AW, Qadr CS, Perkins LM, Walenna MA. Deformation and Compression Behaviour of a Cement-Bentonite Slurry for Groundwater Control Applications. Geotechnical and Geological Engineering. 1;36(2):835$53,2018$.

[21] Jefferis SA. The origins of the slurry trench cut-off and a review of cement-bentonite cut-off walls in the UK. No. CONF-970208--PROC. 1997.

[22] BSI 1377-7-1990. Methods of test for soils for civil engineering purposes-Part 7: Shear strength tests (total stress). London: UK: British Standard institute 1990.

[23] Standard AS. D2166. "Standard Test Methods for Unconfined Compressive Strenght of Cohesive Soil", (ASTM International), West Conshohocken, PA, 2006, DOI: 10.1520/D2166-06. 
[24] British Standards Institution. Methods of Test for Soils for Civil Engineering Purposes: Shear Strength Tests (effective Stress) (British Standards Institution), London, 1990.

[25] EN B. 1097-5: 2008 Tests for mechanical and physical properties of aggregates. Determination of the water content by drying in a ventilated oven (British Standards Institution), London, 2008.

[26] BSI 1377-2: 1990. British standard methods of test for soil for engineering purposes: Classification tests (British Standard institute), London, 1990.

[27] Mitchell JK, Soga K. Fundamentals of soil behavior (John Wiley \& Sons), New York, 2005. 